\title{
QUEBRA DE CONTRATO — TRANSPARÊNCIA E OPACIDADE DO DISCURSO HISTORIOGRÁFICO
}

\author{
Mônica Gama ${ }^{1}$
}

FARGE, Arlette. O Sabor do Arquivo. Trad. Fátima Murad. São Paulo: Edusp, 2009.

Quando as bibliotecas públicas contavam apenas com aqueles armários cheios de fichas organizadas em ordem alfabética para auxiliar os leitores a encontrarem um determinado livro, havia aquele prazer em passar os dedos em dezenas de fichas e descobrir autores e títulos que, muitas vezes, passavam a interessar mais que aqueles desejados no início da consulta. Para as bibliotecas em que o leitor tem acesso às estantes sem precisar da figura do bibliotecário (figura entre o carcereiro e o marido ciumento que protege o que é desejado por ambos), ainda resta o fascínio de se perder entre as prateleiras e encontrar a esmo algo que não se procurava.

E aquelas fichas de controle que ficavam no fim do livro indicando quando e quem o retirou antes de você? Em muitos momentos eu dividia o tempo de leitura entre o livro e as divagações sobre os desconhecidos que também quiseram ler aquele volume. Reconstituía motivações de leitura; pensava quem era cada um deles e como era a sua rotina; olhava para as datas de retirada e entrega do livro e dividia os leitores em dois grupos: aqueles que obedeciam a prazos de entrega e os que sempre atrasavam ou entregavam antes; imaginava o que a próxima pessoa pensaria sobre o meu nome ali exposto e se ela deixaria o livro de lado por alguns instantes para divagar, como eu, sobre essas questões tão improdutivas.

Talvez essas sejam as experiências mais próximas que um leitor comum tenha do que é a pesquisa em arquivos. É esse prazer de encontrar o buscado, mas também de se deixar encontrar por documentos dos quais não se suspeitava. Ganhamos o dia quando, de repente, achamos um documento do qual não suspeitávamos a existência. Encontrar e escrever sobre um fragmento de manuscrito ou mesmo uma anotação numa margem qualquer parece nos tornar coautores de algo cuja importância só nosso olhar foi capaz de reconhecer (ou mesmo de conceder), de algo que até então passara despercebido a vários outros pesquisadores - algo que ainda podemos dividir com outros por meio de nossa escrita.

A descrição desses hábitos — para muitos, um sinal da ingenuidade do autor deste texto — foi inspirada na leitura do livro O Sabor do Arquivo, de Arlette Farge. Traduzido do francês depois de vinte anos de seu lançamento, esse ensaio sobre a prática da pesquisa em arquivo e seu papel na escrita da história fascina pela forma narrativa escolhida que oscila entre um olhar íntimo para os aspectos materiais da pesquisa e reflexões sobre o fazer historiográfico.

\footnotetext{
${ }^{1}$ Doutoranda do programa de Literatura Brasileira da Universidade de São Paulo (FFLCH-USP). Membro do grupo Criação e Crítica. Contato: gamamonica@yahoo.com.br
} 
Mas se engana quem pensa que se trata de um texto que utiliza o tom pessoal para, retoricamente, seduzir o leitor para a conclusão sobre a positividade do trabalho em arquivos. O que encontramos é a afirmação do corpo no espaço do arquivo. É como o corpo do pesquisador (apagado no texto quando nos referimos a ele apenas por meio de verbos como "pensa", "afirma", "declara", "conclui", entre outros), trava pequenas batalhas diárias com arquivistas e bibliotecários para ter acesso a manuscritos; tem seu ritmo de pesquisa influenciado pela presença de vizinhos de sala de leitura; movimenta-se, num ritual burocrático, em busca de carteirinhas, autorizações e fichas a serem preenchidas; tem seu tato estimulado pela textura de um fragmento de cartaz que ainda tem vestígios da parede onde estava colado no século XVIII.

Nesse sentido, as descrições apaixonadas (e muitas vezes irônicas) das sensações envolvidas no processo de pesquisa constituem passagens divertidas no texto de Farge. Se a visão é essencial para a leitura dos manuscritos (para identificar o local privilegiado da consulta, as cores das fichas e formulários, além da roupa do funcionário que irá ajudar o pesquisador nesse labirinto burocrático), muitas vezes ela é reprimida pelos sons do sapato de alguém ou mesmo pelo barulho das folhas sendo viradas por algum leitor vizinho.

Também o conteúdo de manuscritos pode pôr a visão em cheque. O arquivo, esse reino do silêncio, pode ser abalado por documentos que necessitam da oralização para fazer algum sentido. É o que Farge narra a respeito do caso Thorin, um homem que só se comunicava escrevendo do jeito como falava, ou seja, transcrevia fragmentos de seu raciocínio de tal forma que o entendimento de seus textos só é possível ao efetuar a leitura dos manuscritos em voz alta. A cultura sonora e o conjunto de regras para a leitura pública silenciosa do arquivo se chocam, produzindo o estranhamento da descoberta auditiva do conteúdo escrito.

Esse estranhamento é apenas uma das situações discursivas que se impõem para uma dinâmica diferente de leitura. A lentidão e a paciência também estão sempre presentes, pois, antes de podermos calcular mais precisamente o montante do que será consultado, os manuscritos parecem multiplicar-se infinitamente. Aquilo que num catálogo poderia parecer irrelevante para a pesquisa, pode passar a ser um de seus centros.

Porém, essa definição ainda não será capaz de fazer com que o pesquisador se movimente mais rapidamente entre os manuscritos. Isso porque ele encontra diversos obstáculos que se tornam cruciais para a interpretação: se tivemos o prazer de encontrar uma letra razoavelmente fácil de se ler, resta ainda contar com a sorte para que o tipo de papel usado tenha sido de boa qualidade e/ou armazenado adequadamente para que não se desfaça em nossas mãos; também o tipo de tinta ou lápis é importante para a conservação do conteúdo escrito; é preciso também que o autor não tenha tratado suas rasuras como Graciliano Ramos, queimando palavras e trechos com seu cigarro e impossibilitando-nos o acesso às possibilidades presentes no processo de criação; parece banal, mas é gratificante quando temos todas as páginas de um documento.

Assim, também fazem parte da pesquisa com manuscritos a lentidão e a paciência. Os documentos se revoltam contra nossa ideia de produtividade: são incompletos, contraditórios, ilegíveis e até falsamente fáceis. Eles testam a capacidade de rigor e de imaginação de seu leitor, minando ou confirmando suas 
hipóteses iniciais. Essa relação do pesquisador com seu objeto é focalizada em $O$ sabor do arquivo pela argumentação e pelo modo de enunciação escolhido por Farge.

\section{"Ela” é Arlette Farge?}

No livro, há um modo particular de exposição do material historiográfico sobre a pesquisa com o arquivo judicial do século XVIII. É importante levarmos em conta a forma como o livro se apresenta, resultado de trabalho criativo e de publicidade efetuado geralmente pelo editor (com maior ou menor participação do escritor), que define o modo de circulação da obra. Na orelha e na contracapa há um apelo à leitura do livro por meio da chave da autobiografia intelectual da historiadora em passagens como: "articulando a experiência pessoal da autora com as peculiaridades do trabalho arquivístico", "apaixonada pelos arquivos, Arlette Farge convida o leitor a acompanhá-la em seu prazer quase cotidiano de 'ir aos arquivos"” e "escrita do ponto de vista de uma historiadora tomada pela paixão por arquivos".

Se nesses dois espaços limiares do texto o leitor é preparado para encontrar no livro a voz íntima de Arlette Farge, também o interior do livro, por meio do uso tipográfico, parece confirmar essa expectativa. Isso porque há a oscilação entre o uso da tipografia em itálico e romano para fazer um jogo de aproximação e distanciamento com aquele que escreve. Esse tipo de recurso já fora usado em outros contextos, como é o caso de Tutaméia, livro de contos de Guimarães Rosa. Nessa obra, o autor apresenta quatro prefácios grafados em itálico, indicando, entre outros aspectos, a presença de um discurso autobiográfico.

Assim, os capítulos "Milhares de Vestígios", "Percursos e Presenças", "Os Gestos da Coleta", "Falas Captadas" e "Escrever" estão em tipos romanos. Nesses capítulos temos a reflexão sobre o fazer historiográfico, ou seja, a descrição da materialidade dos documentos, o conteúdo de alguns e os procedimentos para sua leitura e interpretação.

Entremeados a esses cinco capítulos, há outros três em itálico: "Na Porta da Entrada", "Ela Acaba de Chegar" e "A Sala dos Inventários é Sepulcral”. Neles, a autora narra aspectos da sociabilidade no arquivo, descrevendo desde a rotina burocrática para a obtenção do material a ser lido e a busca pela melhor mesa de trabalho, até o despertar de sensações provocadas pela vida em comum do arquivo. Vale ressaltar que por vezes a escrita assume um tom mais literário que historiográfico, tal como na seguinte passagem:

nas salas de arquivos, os cochichos enrugam a superfície do silêncio, os olhos se perdem e a história se decide. O conhecimento e a incerteza misturados se ordenam em uma ritualização exigente onde a cor das fichas, a austeridade dos arquivistas e os cheiros dos manuscritos servem de balizas para um mundo sempre iniciático. Além do manual de instruções, sempre ubuesco, encontra-se o arquivo. A partir daí, começa o trabalho (FARGE, 2009, p. 55).

Mesmo que esse tipo de escrita esteja presente em apenas três das oito partes do ensaio de Farge, percebe-se, até pelo início deste texto, que foi o que mais marcou nossa leitura. Mas o exemplo pode ser 
aproveitado para abordar uma ambiguidade fundamental do discurso da historiadora. Trata-se da ausência do uso da primeira pessoa, assim como de informações e dados sobre a vida pessoal ou mesmo de informações mais detalhadas sobre os funcionários ou consulentes que a cercam. Assim, sem termos o uso do eu ou a declaração de que os hábitos daquela pesquisadora são os de Arlette Farge, resta ao leitor uma situação discursiva ambígua em que, por mais que os paratextos nos indiquem que se trata de uma historiadora “tomada pela paixão dos arquivos", não temos a efetuação de um pacto autobiográfico no interior do livro.

Para cada um dos capítulos em itálico há um sujeito narrado: em "Na Porta de Entrada" narra-se sobre ele, um leitor; em "Ela Acaba de Chegar" conta-se sobre ela, uma pesquisadora, e eles, os vizinhos; por fim, em "A Sala dos Inventários é Sepulcral", narra-se sobre a sala, um rapaz inibido e ela, uma pesquisadora experiente e talvez renomada. Em todos os casos, o narrador não se identifica: não é a leitora comum, mas também não é uma pesquisadora iniciante falando sobre outra iniciante; os vizinhos não têm nome e não se estabelece nenhuma relação de amizade ou companheirismo entre eles; a sala é tomada como sujeito assim como o rapaz perdido que lembra a pesquisadora do primeiro capítulo.

Em dois momentos o narrador surpreende. Primeiro ao contar a saga do rapaz perdido em relação ao que tem que fazer para constituir a genealogia da família. De repente, o objeto da narração se desloca, surgindo um ela que pensa e age: "os olhos passeiam de uma página à outra sem se fixar e se detêm às vezes nos poucos leitores que, com um cartão verde na mão, só vêm aqui para uma breve verificação. Parece que ele [o rapaz] os inveja, pensa ela" (FARGE, 2009, p. 112) e, finalizando a história sobre esse rapaz: "Ele acrescenta, não se sabe por que, que nesse verão voltará ao Escurial para ver os túmulos dos reis... Ela sorriu” (FARGE, 2009, p. 114). Ora, quem é ela que pensa e sorri? Trata-se de Arlette Farge narrando sobre um rapaz para, indiretamente, falar de si por meio do uso da terceira pessoa? Nesse caso, estaríamos no âmbito do discurso autobiográfico em terceira pessoa? As respostas não podem ser definitivas e nem constituiriam um bom modo de aproximação com o texto se apenas fosse resolvido seu problema de classificação.

Cabe ainda questionar como essas passagens narrativas atuam num texto sobre a história. Isso porque se espera que o historiador tenha sempre um discurso de neutralidade, de afastamento necessário para que haja precisão e, nesse sentido, Farge usaria a terceira pessoa para não sugerir uma subjetividade sinônima de falta de rigor. Seria uma explicação simples, mas ela não convence, já que para isso a historiadora poderia simplesmente usar em todo o livro as formas acadêmicas com as quais estamos habituados.

A ambiguidade do lugar discursivo desse ensaio pode ser uma formalização de questões levantadas por ela no que diz respeito à atividade do historiador quando tem como fonte o arquivo.

\section{Encontro com o real: emoção e rigor}

Uma primeira especificidade da pesquisa em arquivos, sobretudo com conteúdo judicial, é que os manuscritos encontrados engendram um efeito de real porque não foram feitos para um leitor posterior, ao contrário do texto impresso publicado, que é intencionalmente dirigido ao público. Trata-se de um "vestígio 
bruto de vidas que não pediam absolutamente para ser contadas dessa maneira, e que foram coagidas a isso porque um dia se confrontaram com as realidades da polícia e da repressão" (FARGE, 2009, p. 13). E ainda: "o arquivo é uma brecha no tecido dos dias, a visão retraída de um fato inesperado. Nele, tudo se focaliza em alguns instantes de vida de personagens comuns, raramente visitados pela história" (FARGE, 2009, p. 14). Assim, produz no leitor a sensação de captação do real "e não mais de examiná-lo através do relato sobre, do discurso de" (FARGE, 2009, p. 15).

Isso não significa que essa focalização de vidas traz à tona uma completude ou a verdade. Antes, o arquivo é constituído por discursos inacabados que diz da verdade: as narrativas e palavras esparsas constituem elementos do real que, "por sua aparição em um determinado momento histórico, produzem sentido. É sobre sua aparição que é preciso trabalhar, é nisso que se deve tentar decifrá-lo" (FARGE, 2009, p. 35).

O problema se coloca aqui: esse efeito de real que emociona não pode ser o único foco da escrita historiográfica, assim como a análise científica também não é suficiente para expressar essa "brecha no tecido dos dias", já que o arquivo tem um "excesso de sentido quando aquele que o lê sente a beleza, o assombro e um certo abalo emocional” (FARGE, 2009, p. 36). Por isso a historiadora entende a emoção como um instrumento capaz de polir a pedra do passado e do silêncio, ou seja, nega-se a omitir sua presença e admite os acontecimentos (ou seus hiatos) históricos como pedras a serem trabalhadas rigorosamente.

Mas o historiador não pode simplesmente procurar se identificar com o que está lendo, pois identificação é um modo que tem o historiador de ser atraído por aquilo que pode reforçar suas hipóteses $a$ priori - passa-se a não ver o que há de diferença e contradição. Além disso, depois de acumular milhares de vestígios de vidas, tende-se a querer descrever, reconstituir com fascínio. Nesse sentido, estar absorvido pelo arquivo pode fazer com que o pesquisador não consiga mais interrogá-lo.

A solução, para Farge, é um movimento contínuo de aproximação e distanciamento com o arquivo. Ela propõe não a identificação, mas a troca, ou seja, reconhecer o que há de estranho e de familiar, deixar a imaginação trabalhar ao lado do rigor. Uma das palavras mais recorrentes em $O$ sabor do arquivo é opacidade, o que nos remete imediatamente ao conceito de Édouard Glissant (2008) e, se nas referências da autora não encontramos seu nome, a relação entre ambos pode ser estabelecida, tal como tentarei sintetizar a seguir.

\section{A opacidade e o fazer historiográfico}

Glissant protesta pelo direito à opacidade através de uma postura de oposição à ideia de sistema e de compreensão. Para ele, a noção de sistema cria hierarquias baseadas na compreensão como método, o que traz consigo um gesto de apropriação do outro. O sujeito que se propõe a compreender termina por se esforçar em transformar a diversidade que observa em um uno explicável.

Para ele, o direito à opacidade pressupõe uma "singularidade não redutível": não se trata do obscuro, "mas pode sê-lo e ser aceito como tal. Ele é o não-redutível, que é a mais vivaz das garantias de participação e confluência" (GLISSANT, 2008, p. 54). Optar pela não redução do diverso pela compreensão 
garante o desvio das verdades absolutas. Glissant, assim, resume seu desejo crítico: "Longe de recuar-me no inútil e no inativo, ele [pensamento da opacidade] relativiza em mim os possíveis de toda ação, sensibilizando-me aos limites de qualquer método" (GLISSANT, 2008, p. 54).

Como vimos, em $O$ sabor do arquivo também há reflexões sobre as armadilhas da centralização do sujeito que acessa o arquivo operando conceitos estabelecidos a priori, que levam o pesquisador a apagar o diverso e, confortavelmente, construir sistemas explicativos.

Resistindo a esse tipo de olhar, a leitura do arquivo constitui-se da iluminação de inúmeros detalhes que emocionam, mas também desorientam. Desiludindo o pesquisador da esperança de "linearidade e de positivismo, a irrupção das palavras e dos atos quebra os modelos estabelecidos, traz o desvio da norma, desloca o sentido adquirido de uma vez por todas e com muita frequência adiciona uma certa confusão ao que se imaginava simples anteriormente" (FARGE, 2009, p. 46).

Daí a ideia de troca proposta pela historiadora. O confronto do pesquisador com a opacidade do manuscrito, primeiro passo para uma leitura mais produtiva, ocorre quando o objeto se mostra irredutível às interpretações convenientes. Da mesma forma, quando um manuscrito é fácil, ou seja, confirma o que se supõe nele facilmente, é preciso desaprendê-lo, rejeitar a simpatia que sugere. Dessa facilidade suposta na leitura de documentos de arquivo resulta uma das críticas feitas por Farge ao fazer historiográfico:

quando o documento se anima a ponto de levar a crer que ele se basta a si mesmo, sobrevém inevitavelmente a tentação de não se desgrudar dele e de fazer um comentário imediato a seu respeito, como se a evidência de seu enunciado não devesse ser reinterrogada. Disso decorre uma escrita da história, descritiva e plana, incapaz de produzir outra coisa que não o reflexo (e mesmo o decalque) do que foi escrito há duzentos anos (FARGE, 2009, p. 73).

A crítica pode ser lida por pesquisadores de qualquer campo que trabalhem com documentação de arquivo. Em crítica literária (e sobretudo em crítica genética ${ }^{2}$ ) a ideia de estarmos diante de uma verdade sobre a produção literária é, ao mesmo tempo, fantasma e tesouro cobiçado.

Dessa forma, muitas vezes os manuscritos dos escritores não são interrogados a fim de desestabilizar os enunciados que comportam, ficando o pesquisador como um refém ou vigilante das verdades sobre uma obra de arte. Refém porque, inserindo-se num campo de estudos sobre um determinado autor, haveria modos mais corretos de aproximação com os manuscritos — como entender a prosa de Guimarães Rosa se não levando em conta o diálogo com os intérpretes do Brasil ou com uma determinada prática de representação? Por outro lado, o pesquisador também pode assumir a figura do vigilante, já que, sem explicitar os pressupostos de sua análise, constrói sistemas de explicação da obra que passam a constituir uma verdade sobre a criação.

\footnotetext{
${ }^{2}$ Muitos estudos baseados na crítica genética, disciplina que se ocupa da reflexão sobre os manuscritos, buscavam a reconstituição do processo de criação por meio da análise de marcas que indicavam a temporalidade das etapas da escrita. Para quem parte desse pressuposto, o uso de arquivos pode constituir uma fonte de enganos, na medida em que o pesquisador pode querer apenas mostrar a "verdade" que o manuscrito lhe atestou.
} 
Tanto no discurso sobre a história quanto no discurso sobre a literatura, é difícil reconhecer as descontinuidades, conflitos e incoerências do que estamos tentando entender. Por isso as sugestões de Farge e Glissant para pensarmos essas questões, que se colocam inicialmente como problemas, se tornam fundamentais para o engendramento de um tipo de leitura. Assim, o modo de interrogação e exposição do material de arquivo investigado é crucial para o que conseguiremos extrair dele. A aparente obviedade desta formulação se deve ao fato de quase nunca questionar que tipo de arquivo está sendo lido pelo pesquisador: o arquivo-reflexo (serve apenas como fonte de informação) e arquivo-prova (útil por concluir demonstrações), ambas formas de se relacionar que parte da ideia de acesso total, de transparência possível vista pelo leitor.

\section{Falta de intimidade}

A ausência do uso de primeira pessoa e de informações de âmbito mais íntimo da vida de Arlette Farge já foram levantados como elementos de um discurso fundado numa ambiguidade. Escrita crítica sobre a história, ao mesmo tempo de um ponto de vista pessoal e neutro, o ensaio parece pôr em funcionamento, por meio do estilo escolhido, a forma de desapossar-se do arquivo, a falta.

O arquivo não é apenas o montante de documentos que lá estão, é, mais que isso, uma falta, uma presença enigmática de descontinuidades e contradições que se colocam como desafio constante. O importante, para Farge, é que "utilizar o arquivo hoje é traduzir essa falta em questão" (FARGE, 2009, p. $58)$.

A materialidade do livro, via paratextos, sugere ao leitor a existência de um contrato, pronto a assinar, de que ele se submeterá a ler um texto autobiográfico; o uso de tipografia diferenciada e a escolha de narrar uma sociabilidade da pesquisa também enviam o leitor a esse campo do relato íntimo. Entretanto, os recursos usados para evitar a pessoalidade, como a presença de sujeitos que podem ou não ser identificados com Arlette Farge, desestabilizam essa indicação de um possível contrato autobiográfico.

O leitor de $O$ sabor do arquivo oscila entre essa aproximação com o ambiente do arquivo e o distanciamento da historiadora que tece reflexões acerca do hábito de pesquisa. Se a dúvida sobre quem narra e o que está sendo narrado permanece durante a leitura, no último capítulo há, sinteticamente, a explicitação desse método fundado na falta, no desarranjo, confronto e aceitação da opacidade do discurso:

Com certeza há meio, pela simples escolha das palavras, de produzir abalos, de desmentir evidências, de inverter o habitual fio indulgente do conhecimento científico. Com certeza há meio de ir além da restituição morna de um acontecimento ou de um objeto histórico, marcando lugares onde o sentido se desfez, produzindo ausência lá onde reinaram certezas (FARGE, 2009, p. 118-119).

Circunscrita entre a paixão e a razão, a desordem e o rigor, a escrita pode partir da ideia da opacidade a ser relatada e, mais, tomada como método para produzir esses abalos. Esse ensaio, ao escolher uma enunciação ambígua, formaliza o que a autora define como o sabor do arquivo ao final do livro: "uma 
errância por meio das palavras de outro, à procura de uma língua que salve suas pertinências" (FARGE, 2009, p. 119). Restabelece, então, a opacidade da linguagem historiográfica que se apresenta falsamente neutra ao esconder a subjetividade das escolhas e formas de aproximação dos acontecimentos. O leitor, sendo o errante em um texto cuja enunciação é comprometida em sua transparência, também sai em busca desse sabor do arquivo pelas palavras de uma linguagem opaca, pois ambígua e inexplicavelmente saborosa. 


\section{Referências Bibliográficas}

GLISSANT, É. "Pela opacidade”. Trad. Henrique Groke e Keila Prado Costa. Revista Criação \& Crítica, n. 1, p. 53-55, 2008. Disponível em:

<http://www.fflch.usp.br/dlm/criacaoecritica/dmdocuments/C_C_N1_TraducaoGlissant.pdf> Acesso em: 10 jan. 2010.

Artigo recebido em: 13/02/2010

Artigo aprovado em: 20/02/2010

Referência eletrônica: GAMA, Mônica. Quebra de contrato — transparência e opacidade do discurso historiográfico, Revista Criação \& Crítica, n. 4, p. 249-257, 2010. Disponível em:

<http://www.fflch.usp.br/dlm/criacaoecritica/dmdocuments/20CC_N4_reMGama.pdf> 